\title{
LAS REFERENCIAS BÍBLICAS EN INGLÉS Y EN ESPAÑOL. ESTUDIO CULTUROLÓGICO- CONTRASTIVO ${ }^{1}$
}

\author{
Lucía Luque Nadal, Universidad de Córdoba \\ Email: fe1luna@uco.es
}

\begin{abstract}
This paper presents a contrastive study between English and Spanish biblical expressions. Through the comparative study of these biblical expressions we can also investigate their culturological aspects. From a culturological point of view we analyse how the biblical culturemes work differently both in English speaking Protestant societies and Spanish speaking Catholic societies. In addition, special attention will be paid to those culturological false friends that can cause problems to translators.

Keywords: Culturology, contrastive phraseology, lexicography

Title in English: Biblical References in English and Spanish. Culturological-Contrastive Studies

Resumen: Este artículo presenta un estudio contrastivo de expresiones bíblicas en inglés y en español a través del cual se investigan los aspectos culturológicos de las mismas. A partir de este análisis culturológico se comprueba además cómo funcionan los culturemas bíblicos tanto en las sociedades protestantes de habla inglesa como en las sociedades cristianas de habla española y se explican sus diferencias y similitudes. Se presta también atención especial a los falsos amigos culturológicos en cuanto que plantean un problema para la traducción de los mismos.

Palabras clave: Culturología, fraseología contrastiva, lexicografía
\end{abstract}

\section{INTRODUCCIÓN}

Aunque las expresiones bíblicas en inglés y en español emanan de una misma fuente, si se profundiza en el significado y en el uso de las expresiones comunes que existen en ambas lenguas se descubre que, aun compartiendo el mismo origen y la misma estructura formal, su significado y los contextos en que dichas expresiones se utilizan distan mucho de ser equivalentes.

Para descubrir y poner de relieve las similitudes y especificidades que existen en las expresiones bíblicas del inglés y el español es necesario realizar un estudio contrastivo y culturológico sistemático de las expresiones bíblicas en ambas lenguas. Mediante la comparación de las expresiones bíblicas en ambas lenguas podemos detectar además los denominados 'falsos amigos culturológicos', es decir, podemos comprobar cómo una

Date of reception: 30 May 2010

Date of acceptance: 14 July 2010

Odisea, $n^{\circ} 11$, ISSN 1578-3820, 2010, 269-283 
misma expresión bíblica es conceptualizada por los hablantes de inglés y de español de diferente manera, siendo por tanto asociada a diferentes valores y utilizada en contextos de uso diferentes.

El estudio de los culturemas bíblicos que aquí se presenta forma parte de un macroproyecto de investigación llevado a cabo por el GILTE (Grupo de Investigación de Lingüística Tipológica y Experimental) de la Universidad de Granada que actualmente trabaja en la elaboración de Diccionarios Interlingüísticos e Interculturales en los cuales tienen especial relevancia la inclusión y explicación de los 'culturemas' más comunes en cada lengua. El estudio de los culturemas bíblicos permite comprobar cómo la lectura que cada lengua y cada cultura europea ha hecho de la Biblia ha dado origen a una serie de similitudes, pero también a una serie de diferencias notables entre los culturemas bíblicos.

En este trabajo se demuestra que las expresiones fraseológicas provenientes de la Biblia son más abundantes en los países de tradición protestante que en los países de tradición católica. La tradición protestante ha permeado en el lenguaje de manera más profunda, manifestándose en la creación de multitud de expresiones de origen bíblico. Muchas de estas expresiones han perdido hoy en día su motivación inicial, es decir, los hablantes las utilizan en su conversación diaria sin percatarse o ser conscientes del origen bíblico de dicha expresión, sobre todo entre los hablantes más jóvenes de la lengua.

\section{DOMINIOS ESPECÍFICOS DE CREACIÓN DE FRASEOLOGISMOS. LA BIBLIA COMO FUENTE COMÚN DE FRASEOLOGISMOS Y CULTUREMAS}

En el aprendizaje de una lengua, ya sea la materna o una segunda lengua, se pueden concretar diversos niveles en cuanto a la dificultad y riqueza del tejido lingüístico. Así, en una primera etapa el hablante comienza aprendiendo y utilizando palabras simples monosémicas (p.ej. cuchara, bota). Esta primera etapa podría denominarse la 'etapa literal'. En una segunda etapa, el tejido lingüístico se vuelve más fino y se derivan significados simbólicos de esos términos monosémicos aprendidos y consolidados en la primera etapa. Es en este segundo nivel donde afloran los fraseologismos, los símbolos, las alusiones, los culturemas, etc. Así, de cuchara y bota tendríamos expresiones como 'entregar la cuchara' (morir), 'ponerse las botas', 'colgar las botas', etc.

Además de crear fraseologismos y culturemas a partir de palabras comunes de la vida diaria, el hablante toma como referencia otros campos o dominios más específicos y culturales como son la religión, la Biblia, la tradición clásica, la historia, el folklore nacional, la cuentística, etc.

Las expresiones bíblicas conforman una historia común europea. Es por ello que comparaciones inglesas de origen bíblico como as wise as Solomon, as old as Methuselah, as poor as Lazarus, as proud as Lucifer, as old as Adam, etc., sean prácticamente iguales en español y otras lenguas europeas. No obstante, en algunos casos puede ocurrir que una determinada lengua europea subraye una característica determinada de un personaje bíblico que otras lenguas no destacan. Así por ejemplo, de la figura de Job en inglés se destacan dos cualidades (la paciencia y la pobreza) donde en español solo se destaca una (la paciencia). Por ello, en inglés 
existen dos expresiones en las que aparece el personaje de Job ${ }^{2}$ : as patient as Job y as poor as $J o b$, mientras que en español solo existe la expresión tener más paciencia que el santo Job.

Esta serie de expresiones bíblicas tienen diversas denominaciones en español. Carmen Mellado Blanco (2007) denomina bibleismos a la serie de fraseologismos derivados de la Biblia. Otros autores utilizan también el término biblismos o biblecismos. Acerca de la estructura de los bibleismos Mellado Blanco afirma que estos no han de ser citas textuales del texto bíblico sino que surgen como condensación de los pasajes bíblicos. Así:

Como ya hemos dicho anteriormente, los bibleismos situacionales no están citados palabra por palabra a partir del texto original, sino que han surgido como condensación de un determinado pasaje bíblico. Una parte de los bibleismos situacionales estudiados del alemán y el español tienen equivalencia interlingual, e incluso revelan la misma marca estilística de ironía: im Schweiße meines Angesichts / ganarse algo con el sudor de su frente (Génesis 3:19), den Schlaf des Gerechten schlafen / dormir el sueño de los justos (Libro de los Proverbios 24:15); verirrtes Schaf / oveja descarriada (1 ${ }^{\text {a }}$ Epístola de San Pedro 2:25); Der Geist ist willig, [aber] das Fleisch ist schwach / [El espíritu es animoso] pero la carne es débil (San Mateo 26:40), Der Mensch lebt nicht vom Brot allein / No solo de pan vive el hombre (San Mateo 4:4). Mellado (2007:102-103)

La importancia que los bibleismos tienen en todas las lenguas europeas, y en especial en los países protestantes, ha sido explicada por Piirainen (2007:209) por el hecho de que, tras la invención de la imprenta, la Biblia fue el único libro disponible en muchas familias, sobre todo en los países protestantes. El hecho de ser el único libro existente en la mayoría de los hogares hizo que la lectura diaria de pasajes enteros fuera algo habitual. Además, la lectura repetida de la Biblia hacía también que muchos de los pasajes bíblicos fueran aprendidos de memoria. Por está razon, afirma Piirainen que bibleismos ingleses como built on sand / construido sobre la arena (Mateo 7,26), swim against the tide/nadar en contra de la corriente (Sirach/Eclesiástico 4,3133) o take someone under one's wing/tomar a alguien bajo sus alas (Salmos 91,4), existan en casi todas las lenguas europeas.

Siguiendo la explicación de Piirainen es fácil constatar que la influencia de la Biblia en las comparaciones proverbiales en inglés es mayor que las correspondientes en español, dado el mayor contacto y familiaridad existentes entre los hablantes de lengua inglesa y el Libro Sagrado. Esta familiaridad y buen conocimiento de los textos bíblicos ha hecho que los hablantes de lengua inglesa hayan derivado o condensado expresiones, proverbios y enseñanzas allí donde los hablantes españoles solo se limitan en ocasiones a conocer quizás las citas literales tomadas de la Biblia. Así por ejemplo, la mayoría de los españoles probablemente conozcan la frase que Dios dice a Abraham "yo te bendeciré y multiplicaré tu descendencia como las estrellas del cielo y las arenas del mar" (Génesis 22, 1-2. 9a.13.15-18). No obstante, esta frase no puede considerarse una expresión proverbial puesto que no se utiliza en el lenguaje diario de la calle y cuando aparece en un texto, este tiene

\footnotetext{
2 Los ejemplos ingleses podrían indicar acaso una lectura más atenta y completa de las vicisitudes de este personaje bíblico.

3 En la Biblia española (Sagrada Biblia de Nácar Fuster, E. y Colunga, A. (1963), Biblioteca de Autores Cristianos. Madrid) corresponde al Eclesiástico 4:32 ya que ésta divide los versículos de manera diferente a como lo hacen las Biblias protestantes.
} 
un carácter especial, religioso o literario. En inglés, sin embargo, de este mismo pasaje sí se ha derivado la comparación estereotipada as numberless as the sands, expresión muy usual en inglés ${ }^{4}$.

\subsection{Bibleismos en diferentes idiomas europeos}

Como se ha indicado, la herencia común de la Biblia en Europa hace que los fraseologismos de origen bíblico abunden en todos los idiomas europeos ${ }^{5}$. Véase por ejemplo: Esp. Ojo por ojo, diente por diente (Éxodo, 21, 23-25); Ing. An eye for an eye, and a tooth for a tooth; It. Occhio per occhio, dente per dente; Fr. Eil pour xil, dent pour dent; Al. Auge für Auge, Zahn für Zahn; Pt. Olho por olho, dente por dente; Rus. Око за око, зуб за зуб.

En los siguientes ejemplos de bibleismos en diferentes lenguas europeas pueden notarse algunas diferencias formales, casi siempre leves, de los fraseologismos bíblicos.

Bibleismos en francés:

\begin{tabular}{|l|l|l|}
\hline EXPRESIÓN FRANCESA & EXPRESIÓN ESPAÑOLA & PASAJE BÍBLICO \\
\hline Jeter la première pierre & Arrojar la primera piedra & Juan 8, 7 \\
\hline Un baiser de Judas & Beso de Judas & Mateo 26, 48-49 \\
\hline Vieux comme Mathusalem & $\begin{array}{l}\text { Viejo como Matusalén/ Más } \\
\text { viejo que Matusalén }\end{array}$ & Génesis 5, 27 \\
\hline Les années de vaches maigres & Época de vacas flacas & Génesis 41, 1-36 \\
\hline $\begin{array}{l}\text { Les premiers seront les } \\
\text { derniers }\end{array}$ & Los últimos serán los primeros & Mateo 19, 30 \\
\hline $\begin{array}{l}\text { Beaucoup d'appelés, peu } \\
\text { d'élus }\end{array}$ & $\begin{array}{l}\text { Muchos son los llamados y } \\
\text { pocos los elegidos }\end{array}$ & Mateo 22, 1-14 \\
\hline La paille et la poutre & La paja y la viga & Mateo 7, 3-5 \\
\hline $\begin{array}{l}\text { L'homme ne vit pas que de } \\
\text { pain }\end{array}$ & No solo de pan vive el hombre & $\begin{array}{l}\text { Deuteronomio 8, 3 y } \\
\text { Mateo 4, 3-4 }\end{array}$ \\
\hline $\begin{array}{l}\text { Qui sème le vent récolte la } \\
\text { tempête }\end{array}$ & $\begin{array}{l}\text { Quien siembra vientos recoge } \\
\text { tempestades }\end{array}$ & Oseas 8, 7 \\
\hline $\begin{array}{l}\text { Gagner son pain à la sueur } \\
\text { de son front }\end{array}$ & $\begin{array}{l}\text { Ganar el pan con el sudor de su } \\
\text { frente }\end{array}$ & Génesis 3, 19 \\
\hline
\end{tabular}

\footnotetext{
4 Así, en la novela In the Cage de Henry James (1908) encontramos el siguiente pasaje: "Her function was to sit there with two young men- the other telegraphist and the counter-clerk; to mind the "sounder", which was always going, to dole out stamps and postal-orders, weigh letters, answer stupid questions, give difficult change and, more than anything else, count words as numberless as the sands of the sea".

5 Sabban (2007:595) considera que no solo la Biblia constituye un ejemplo de elementos de la herencia común europea sino que también habría que tener en cuenta la mitología y parte de la literatura antigua y moderna. Así, Sabban cita la caja de Pandora que existe en francés (la boîte de Pandora), inglés (Pandora’s box) y alemán (die Büchse der Pandora).
} 
Bibleismos en alemán:

\begin{tabular}{|l|l|l|}
\hline EXPRESIÓN ALEMANA & EXPRESIÓN ESPAÑOLA & PASAJE BÍBLICO \\
\hline Alt wie Methusalem & $\begin{array}{l}\text { Viejo como Matusalén/ Más viejo que } \\
\text { Matusalén }\end{array}$ & Génesis 5, 25 \\
\hline Für ein Linsengericht & $\begin{array}{l}\text { (Vender la primogenitura) por un plato } \\
\text { de lentejas }\end{array}$ & Moisés 25,34 \\
\hline $\begin{array}{l}\text { Eher geht ein Kamel duch ein } \\
\text { Nadelöhr }\end{array}$ & $\begin{array}{l}\text { Antes pasa un camello a través del ojo } \\
\text { de una aguja }\end{array}$ & Mateo 19, 24 \\
\hline Ein Stein des Anstoßes & Piedra de toque $^{6}$ & Jes 8,12-15 \\
\hline
\end{tabular}

\section{Bibleismos en italiano:}

\begin{tabular}{|l|l|l|}
\hline EXPRESIÓN ITALIANA & EXPRESIÓN ESPAÑOLA & PASAJE BÍBLICO \\
\hline $\begin{array}{l}\text { Padre, perdonali perche' non } \\
\text { sanno quello che fanno }\end{array}$ & $\begin{array}{l}\text { Padre perdónales porque no saben lo } \\
\text { que hacen }\end{array}$ & Lucas 23,34 \\
\hline $\begin{array}{l}\text { Nessuno e' gradito profeta } \\
\text { nella sua patria }\end{array}$ & Nadie es profeta en su tierra & Lucas 4, 24-30 \\
\hline $\begin{array}{l}\text { Chi semina vento raccoglie } \\
\text { tempesta }\end{array}$ & $\begin{array}{l}\text { Quien siembra vientos recoge tempes- } \\
\text { tades }\end{array}$ & Oseas 8,7 \\
\hline Colosso dai piedi di argilla & Coloso de pies de barro & Daniel 2, 33-34 \\
\hline $\begin{array}{l}\text { Il tempo delle vacche magre e } \\
\text { grasse }\end{array}$ & Tiempo de vacas flacas y gordas & Génesis 41, 1-4 \\
\hline $\begin{array}{l}\text { E'piu'facile che un cammello } \\
\text { passi per la cruna di un'ago } \\
\text { che un ricco entri nel regno } \\
\text { dei cieli }\end{array}$ & $\begin{array}{l}\text { Es más fácil que un camello pase por el } \\
\text { ojo de una aguja que un rico entre en el } \\
\text { reino de los cielos }\end{array}$ & Mateo 19, 24 \\
\hline $\begin{array}{l}\text { Beati } i \text { poveri di spirito, per- } \\
\text { che' di essi e'il regno dei cie- }\end{array}$ & $\begin{array}{l}\text { Bienaventurados los pobres de espíritu } \\
\text { porque de ellos es el reino de los cielos }\end{array}$ & Mateo 5,3 \\
\hline $\begin{array}{l}\text { Non di solo pane vive l'uomo } \\
\text { ma di ogni parola che procede } \\
\text { dalla bocca di Dio }\end{array}$ & $\begin{array}{l}\text { No solo de pan vive el hombre (sino } \\
\text { de toda palabra que sale de la boca de } \\
\text { Dios) }\end{array}$ & Mateo 4, 3-4 \\
\hline
\end{tabular}

\footnotetext{
6 La piedra de toque era el método que se utilizaba para probar artesanalmente la ley del oro y la plata. La expresión ha quedado para referirse a aquello que sirve para comprobar la calidad de otra cosa.

7 En italiano como en español abundan las expresiones religiosas no estrictamente bíblicas: Ognuno porta la sua croce (Cada uno lleva su cruz), Scoprire un altare per ricoprirne un altro (Desvestir un santo para vestir a otro), Di buona volantà sta pieno l'inferno (El camino del infierno está empedrado de buenas intenciones). Este último expresa la opinión popular de que las buenas intenciones no son suficientes o no justifican unos malos resultados. Contrasta con el dicho 'Lo que importa es la intención'.
} 


\section{Bibleismos en ruso:}

\begin{tabular}{|l|l|l|}
\hline EXPRESIÓN RUSA & EXPRESIÓN ESPAÑOLA & PASAJE BÍBLICO \\
\hline $\begin{array}{l}\text { Камня на камне не оста- } \\
\text { вить (от чего-л.) }\end{array}$ & No dejar piedra sobre piedra & Lucas 21,6 \\
\hline Содом и гоморра & Sodoma y Gomorra & Génesis 19, 1-29 \\
\hline $\begin{array}{l}\text { Правая рука не знает, что } \\
\text { делает/творит левая }\end{array}$ & $\begin{array}{l}\text { Que la mano derecha no sepa lo que } \\
\text { está haciendo la izquierda }\end{array}$ & Mateo 6, 3-4 \\
\hline Альфа и омега (чего-л.) & Alfa у omega & Apocalipsis 1,8 \\
\hline
\end{tabular}

Bibleismos en polaco

\begin{tabular}{|l|l|l|}
\hline EXPRESIÓN POLACA & EXPRESIÓN ESPAÑOLA & PASAJE BÍBLICO \\
\hline $\begin{array}{l}\text { Tak ostatni będa pierwszymi, a } \\
\text { pierwsi ostatnimi }\end{array}$ & $\begin{array}{l}\text { así, los últimos serán primeros y } \\
\text { los primeros, últimos }\end{array}$ & Mateo 20, 16 \\
\hline $\begin{array}{l}\text { Będziesz miłowat swego bliźniego } \\
\text { jak siebie samego }\end{array}$ & $\begin{array}{l}\text { Amarás a tu prójimo como a ti } \\
\text { mismo }\end{array}$ & Mateo 12, 31 \\
\hline $\begin{array}{l}\text { Marność nad marnościami- } \\
\text { wszystko marność }\end{array}$ & $\begin{array}{l}\text { ¡Vanidad de vanidades, todo va- } \\
\text { nidad! }\end{array}$ & Eclesiastés 1,2 \\
\hline
\end{tabular}

\section{REFERENCIAS BÍBLICAS EN INGLÉS Y EN ESPAÑOL. ESTUDIO CONTRASTIVO}

Con respecto a la transmisión de los fraseologismos bíblicos, es fácil constatar que existen diferencias entre las distintas lenguas. Estas diferencias son cuantitativas, y así comprobamos que en la lengua inglesa existe una abundancia mucho mayor de bibleismos que en español. Podríamos pensar en la abundancia de referencias bíblicas en inglés como expresión de un rasgo de la cultura inglesa. La razón de esto no es otra que el hecho de que la Biblia ha sido y es todavía el libro de cabecera de muchos angloparlantes desde los últimos 400 años. Sin embargo, en España y en Latinoamérica no se ha tenido acceso directo a la Biblia hasta épocas relativamente recientes y en cualquier caso, salvo los modernos grupos evangélicos etc., prácticamente nadie tiene la costumbre de leer periódicamente la Biblia.

Una situación parecida ocurre si se comparan dos lenguas europeas como el ruso y el francés. Según Gak (1998: 240 y ss), las diferencias que pueden existir entre expresiones bíblicas en ruso y en francés radican en las diferentes formas de tomar prestadas locuciones de la Biblia en Rusia y en Francia. En el ruso, debido a la existencia de una sola versión autorizada de la Biblia y de la liturgia, abundan las citas literales, a diferencia del francés. Gak señala asimismo que en el habla cotidiana de los rusos abundan mucho más los fraseologismos bíblicos que en el habla cotidiana francesa. Este ejemplo propuesto por Gak puede aplicarse a la realidad de los pueblos de habla inglesa y a la realidad hispánica. En inglés encontramos un número mucho mayor de bibleismos porque los hablantes ingleses tienen un contacto mucho mayor con la Biblia que los hispanohablantes. Así se explica la existencia de multitud de expresiones bíblicas inglesas que no existen en español. 
Para realizar el estudio comparativo de los bibleismos en inglés y en español no vamos a realizar una comparación de expresiones bíblicas literales sacadas de diferentes versiones de la Biblia, sino que vamos a trabajar con las expresiones fijas estereotipadas que se han derivado de diferentes pasajes bíblicos. Por tanto, nuestro objetivo es estudiar la significación y los contextos de uso que dichas expresiones bíblicas tienen en la lengua viva.

\subsection{Expresiones bíblicas comunes en español y en inglés}

Aunque la misma lectura de la Biblia por españoles e ingleses no derive necesariamente en las mismas expresiones, encontramos que el inglés y el español tienen un conjunto extenso de bibleismos comunes, es decir, ambas lenguas subrayan el mismo hecho bíblico con las mismas implicaciones. A continuación se muestran aquellas expresiones bíblicas en inglés y en español que comparten la misma forma y el mismo significado ${ }^{8}$ :

\begin{tabular}{|c|c|c|}
\hline EXPRESIÓN INGLESA & EXPRESIÓN ESPAÑOLA & PASAJE BÍBLICO \\
\hline $\begin{array}{l}\text { go through the eye of a nee- } \\
\text { dle }\end{array}$ & pasar por el ojo de una aguja & Mateo 19:23-24 \\
\hline $\begin{array}{l}\text { we see the straw in the eyes of } \\
\text { others and we do not see the } \\
\text { beam in ours }\end{array}$ & $\begin{array}{l}\text { ver la paja en el ojo ajeno y no ver } \\
\text { la viga en el propio }\end{array}$ & Mateo 7,3 \\
\hline cast pearls before swine & $\begin{array}{l}\text { echar perlas } / \text { margaritas }^{9} \text { a los cer- } \\
\text { dos }\end{array}$ & Mateo 7, 6 \\
\hline dove of peace & paloma de la paz & Génesis 8: 8-12 \\
\hline faith will move mountains & la fe mueve montañas & Mateo 17:20 \\
\hline the first shall be last & los últimos serán los primeros & Mateo 20:16 \\
\hline they know not what they do & $\begin{array}{l}\text { perdónales señor porque no saben } \\
\text { lo que hacen }\end{array}$ & Lucas 23:34 \\
\hline the flesh is weak & la carne es débil & Mateo 26:40-41 \\
\hline flesh of my flesh & carne de mi carne & Génesis 2:23 \\
\hline forbidden fruit & la fruta prohibida & Génesis 3:1-16 \\
\hline know them by their fruits & por sus frutos los conoceréis & Mateo 7:16-20 \\
\hline fallen angel $^{10}$ & el ángel caído & Isaías 14:12 \\
\hline faith, hope, and charity & fe, esperanza y caridad & Corintios 13:13 \\
\hline $\begin{array}{l}\text { dust thou art, and unto dust } \\
\text { shalt thou return }{ }^{11}\end{array}$ & $\begin{array}{l}\text { polvo eres y en polvo te converti- } \\
\text { rás }\end{array}$ & Genesis $3: 19$ \\
\hline
\end{tabular}

8 Las expresiones utilizadas en este trabajo están sacadas de diversos diccionarios ingleses de fraseologismos y diccionarios de expresiones bíblicas. Como se ha indicado anteriormente, lo que se compara no son los pasajes bíblicos literales sino la expresión fija estereotipada que se ha derivado del mismo.

9 Véase el apartado 5 para la explicación de la dicotomía perlas/margaritas en la expresión española.

10 Expresión utilizada para designar a 'una persona que ha sufrido un debacle en su fortuna o un declive en su reputación'.

11 Actualmente en inglés se utiliza una versión reducida de la referencia bíblica: dust to dust o también ashes to ashes. 


\begin{tabular}{|l|l|l|}
\hline $\begin{array}{l}\text { four Horsemen of the Apoca- } \\
\text { lypse }\end{array}$ & los cuatro jinetes de la Apocalipsis & Apocalipsis 6:1-8 \\
\hline daily bread & el pan nuestro de cada día & Mateo 6:11 \\
\hline deliver us from evil & líbranos del mal & Mateo 6:13 \\
\hline in the sweat of thy face & con el sudor de su frente & Génesis 3:19 \\
\hline
\end{tabular}

También existen en inglés y en español una serie de expresiones proverbiales bíblicas comunes como por ejemplo: let him who is without sin cast the first stone (Juan 8:7) o en español 'aquel que esté libre de pecado que tire la primera piedra'. Esta expresión se utiliza en ambos idiomas para implicar que no se debe criticar a los demás cuando uno puede ser igualmente culpable de las mismas faltas.

\subsubsection{Antropónimos y topónimos bíblicos en inglés y en español}

Mención especial tienen los antropónimos, sobre todos aquellas parejas de nombres que representan en muchos casos valores opuestos, generalmente uno positivo frente a uno negativo. En inglés y en español existe la asociación Cain and Abel. En inglés existen expresiones derivadas como curse of Cain o brand of Cain, que también aparecen en español como 'la marca de Caín' o 'la maldición de Caín'. También existe en las dos lenguas la expresión David and Goliath (Samuel 17:49) para referirse a una 'competición desigual'.

Dentro de los antropónimos encontramos también algunos personajes a los que se les atribuye una característica especial, a veces explícita en la expresión bíblica a veces implícita. Así tenemos la expresión explícita sobre Job que en ambas lenguas está relacionado con la paciencia: patience of Job, paciencia de Job, tener más paciencia que el santo Job. $\mathrm{O}$ de manera explícita el personaje de Judas como prototipo de traidor: kiss of Judas; beso de Judas.

También los topónimos en la Biblia tienen una relevancia especial. A veces solo el nombre de un lugar alude a una serie de características especiales. Así por ejemplo, la expresión inglesa road to Damascus o la española camino a Damasco lleva implícita la idea de 'cambio repentino aunque verdadero de opinión'. Esta expresión está basada en la historia bíblica que aparece en el capítulo 9 de los Hechos de los Apóstoles donde se narra el viaje de Saulo a Damasco para perseguir a los cristianos. En un momento del viaje Saulo es derribado por un rayo y cae a tierra, quedándose ciego. Los cristianos de Damasco lo recogen y junto a ellos Saulo ve por fin la verdadera fe, es decir se convierte al cristiano y cambia su nombre por el de Pablo. Así, la alusión a la ciudad de Damasco o a cualquiera de los hechos acaecidos en ella sirve para indicar el cambio radical de creencias y actitud de una persona. En español existe también la expresión 'caída del caballo' que se basa también en la misma historia.

\footnotetext{
12 Los cuatro jinetes son personificaciones de la guerra, el hambre, la peste y la muerte (Manser, 2006:136). No obstante, algunos autores indican que el primer jinete, quien posee un caballo blanco, es la representación de Cristo y este a su vez representa la victoria. Así, en la Sagrada Biblia de Nácar Fuster y y Colunga (1963:1273) se expone que "el color del caballo blanco indica victoria y salud $(19,11)$ y representa a Jesucristo, o más bien a sus apóstoles y ministros que llevan el Evangelio por el mundo, que han logrado ya grandes triunfos, pero que aún alcanzarán otros mayores".
} 


\subsection{Expresiones bíblicas específicas en inglés}

No obstante, también ocurre y con mucha frecuencia que el inglés utilice expresiones derivadas de la Biblia que son desconocidas para el lector español. A veces puede suceder que el lector español esté familiarizado con el hecho bíblico pero que en español, al no haber derivado necesariamente en ninguna expresión fraseológica, no se le conceda mayor importancia. Expresiones bíblicas que tienen una relevancia especial en inglés son por ejemplo:

\begin{tabular}{|c|c|}
\hline $\begin{array}{l}\text { EXPRESIÓN BÍBLICA ESPE- } \\
\text { CÍFICA DEL INGLÉS }\end{array}$ & SIGNIFICADO \\
\hline bread of affliction $^{13}$ & Sufrimiento o problemas. \\
\hline bricks without straw ${ }^{14}$ & $\begin{array}{l}\text { Trabajo que se ha de hacer en condiciones difíciles o sin } \\
\text { los materiales necesarios. }\end{array}$ \\
\hline broken reed $^{15}$ & Una persona o cosa débil o dañada. \\
\hline day of small things ${ }^{16}$ & $\begin{array}{l}\text { Detalles aparentemente insignificantes que con el tiempo } \\
\text { se demuestra que han sido el comienzo de grandes em- } \\
\text { presas. }\end{array}$ \\
\hline a dog returneth to his vomit ${ }^{17}$ & Los criminales vuelven a repetir sus fechorías. \\
\hline feet of clay ${ }^{18}$ & $\begin{array}{l}\text { Un defecto de carácter que no es conocido a primera vista, } \\
\text { en alguien que uno admira. }\end{array}$ \\
\hline clay in the potter's hand ${ }^{19}$ & Maleable, fácilmente moldeable. \\
\hline cast thy bread upon the waters ${ }^{20}$ & Dar generosamente. \\
\hline eyeless in Gaza $^{21}$ & En estado de indefensión en un entorno hostil. \\
\hline house of many mansions ${ }^{22}$ & $\begin{array}{l}\text { Un edificio grande; una organización o entidad que ofrece } \\
\text { posibilidades y oportunidades diversas. }\end{array}$ \\
\hline let my people go ${ }^{23}$ & $\begin{array}{l}\text { Es una petición de clemencia a alguien que impone su } \\
\text { voluntad sobre los demás. En el uso moderno la frase se } \\
\text { usa a veces de manera irónica. }\end{array}$ \\
\hline leaven the lump ${ }^{24}$ & $\begin{array}{l}\text { Redimir algo muy grande introduciendo un pequeño ele- } \\
\text { mento bueno. }\end{array}$ \\
\hline land flowing with milk and honey ${ }^{25}$ & $\begin{array}{l}\text { Al principio se refiere a la tierra prometida, a la tierra de } \\
\text { Canaán. En general se usa para cualquier lugar que tenga } \\
\text { buenas condiciones de vida. }\end{array}$ \\
\hline
\end{tabular}

\footnotetext{
Reyes 22:27

Éxodo 5:6-7

Isaías $36: 6$

Zacarías 4:10

Proverbios 26:11

18 Daniel 2:31-33

19 Jeremías 18:6

20 Eclesiastés 11:1

Jueces 16:1-3

Juan 14:2

Éxodo 5:1

24 Corintios 5:6

25 Éxodo 3:8
} 


\begin{tabular}{|c|c|}
\hline devils believe and tremble ${ }^{26}$ & $\begin{array}{l}\text { Incluso las personas más malvadas tienen conciencia del } \\
\text { bien capaz de atormentarlos }\end{array}$ \\
\hline the desert shall blossom ${ }^{27}$ & La tierra volverá algún día a sus propietarios legítimos \\
\hline kill the fatted calf ${ }^{28}$ & Ofrecer al huésped lo mejor que se tiene \\
\hline drop in the ocean ${ }^{29}$ & $\begin{array}{l}\text { Una cantidad ínfima en comparación a la cantidad que se } \\
\text { necesita. }\end{array}$ \\
\hline gird up thy loins ${ }^{30}$ & Prepararse para la acción. \\
\hline fire and brimstone $e^{31}$ & $\begin{array}{l}\text { Amenaza fanática de condenación eterna o de otros cas- } \\
\text { tigos divinos. }\end{array}$ \\
\hline good thing come out of Nazareth ${ }^{32}$ & $\begin{array}{l}\text { Algo bueno que proviene de un sitio o persona inespera- } \\
\text { damente. }\end{array}$ \\
\hline $\begin{array}{l}\text { hewers of wood and drawers of wa- } \\
\text { ter }^{33}\end{array}$ & Aquellos que tienen trabajos humildes y duros. \\
\hline kick against the pricks ${ }^{34}$ & $\begin{array}{l}\text { Protestar y resistirse contra la opinión dominante o la si- } \\
\text { tuación dominante. }\end{array}$ \\
\hline go the way of all flesh ${ }^{35}$ & Morir. \\
\hline crooked shall be made straight ${ }^{36}$ & Al final todos los problemas se solucionarán. \\
\hline
\end{tabular}

Además, en inglés también existe una serie de expresiones proverbiales bíblicas que no existen en español. Así: if the blind lead the blind, both shall fall into the ditch ${ }^{37}$ que se utiliza para referirse a 'una situación en la que los que dirigen son tan ignorantes y desconocedores como los que son dirigidos'; not to know someone from Adam ${ }^{38}$, expresión que se utiliza cuando alguien 'no sabe de la identidad de una persona'; a leopard cannot change its spots $^{39}$ expresión que se utiliza para indicar que 'es imposible que una persona cambie en aquello que es esencial a su carácter'.

Dentro de este grupo de bibleismos específicos del inglés hay que hacer una mención especial, como ya se hizo en el apartado anterior, a los antropónimos. En inglés existen pares de nombres propios que han adquirido una significación especial y que en español, aunque se les conozca, no se les atribuye ningún valor especial. Así por ejemplo David and Bathsheba ${ }^{40}$ son el prototipo de 'un amor culpable'; David and Jonathan ${ }^{41}$ son el ejemplo de 'amistad

\footnotetext{
26 Santiago 2:19

27 Isaías 35:1-2

28 Lucas 15:23

29 Isaías 40:15

30 Reyes 18:46

31 Génesis 19:24

32 Juan 1:46

33 Josué 9:23-27

34 Hechos 9:5

35 Reyes 2:2

36 Isaías 40:4

37 Mateo 15:14.

38 Génesis 2:19.

39 Jeremías 13:23

40 Samuel 11, 12.

41 Samuel 18:1.
} 
entre dos personas'; Gog and Magog ${ }^{42}$ representan a 'las fuerzas impías que, con la guerra, amenazan causar el fin del mundo', etc. Existen además otras expresiones que contienen nombres propios. Así, la expresión burden of Isaiah ${ }^{43}$ se utiliza para designar una 'profecía de desastre'; Belshazzar's palsy ${ }^{44}$ se refiere a un tipo de fiebre, especialmente aquella causada por el miedo; Jacob's ladder ${ }^{45}$ designa 'una escalera de cuerda usada para subir a un barco'; Balaam's ass ${ }^{46}$ es 'algo que sirve para recordar a una persona la manera correcta de actuar'; doubting Thomas ${ }^{47}$ se utiliza para designar a 'aquellas personas que no se convencen hasta que no tiene pruebas'; Cain's city ${ }^{48}$ es 'una ciudad con una reputación de corrupción' y finalmente Adam's profession ${ }^{49}$ es otra designación para 'jardinería o agricultura'.

\section{INTERTEXTUALIDAD DE LOS CULTUREMAS BÍBLICOS}

Unas de las características más sobresalientes de los culturemas en general es su vitalidad, figuratividad y motivación dentro de la comunidad lingüística. Un rasgo donde se comprueba la vitalidad de un culturema es en su aparición en manifestaciones lingüísticas de diversa índole como chistes, títulos de canciones, títulos de películas, etc. Así, según Luque Nadal (2009: 105),

los culturemas han de ser transparentes en su motivación, es decir, la idea nuclear que subyace a diferentes dichos o expresiones relacionadas con el culturema tiene que estar 'viva' para los hablantes. [...] Por tanto, para considerar la existencia de un culturema es indispensable que exista un conocimiento generalizado de algunas implicaciones simbólicas del mismo. Así, temas antiguos como el paraíso y el infierno, San Pedro guardián de las puertas del cielo, o Satanás recibiendo a los pecadores y condenados, son todavía culturemas productivos sobre los que se siguen haciendo chistes o anuncios.

Según esto, para que una expresión bíblica pueda ser considerada un culturema ha de actuar como moneda de cambio en una sociedad y tiene que aparecer en títulos de libros, títulos de películas, letras de canciones, chistes, titulares de periódicos, textos argumentativos, etc. Pensemos por ejemplo en la expresión inglesa chariot of fire (Reyes 2:11). Esta expresión se utiliza en inglés con el significado de 'una manera aparentemente milagrosa de superar un obstáculo'. Si pensamos en títulos de libros, películas, poemas, etc., rápidamente asociamos la expresión chariot of fire a muchos de ellos. Así, en el poema de William Blake titulado Jerusalem ${ }^{50}$ que aparece el verso 'bring me my chariot of fire'. Posteriormente, ya en el siglo XX, encontramos la película titulada Chariots of Fire (1981).

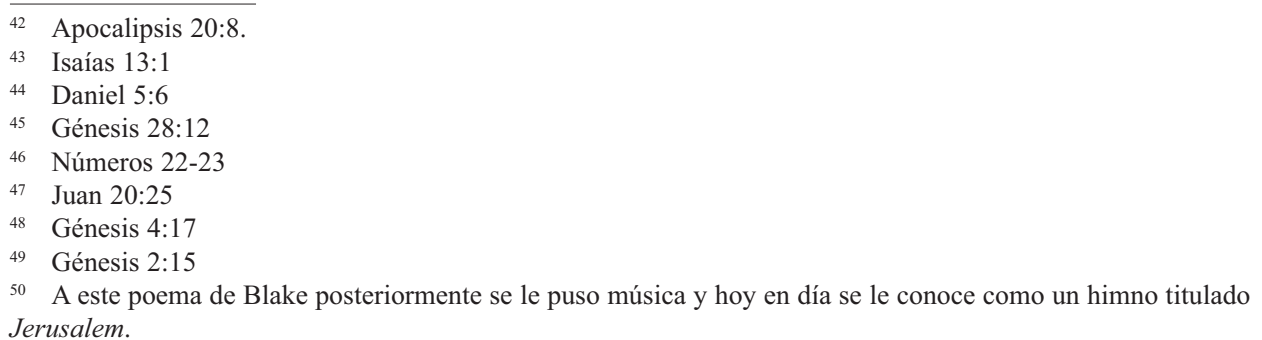


Otra expresión muy productiva en inglés es The grapes of wrath. Esta ha dado origen a una novela de John Steinbeck con el título Grapes of Wrath (1939). Un año después de la publicación de la novela se hizo una película de título homónimo dirigida por John Ford (1940). Además esta expresión también aparece en una canción muy conocida por todos los americanos ${ }^{51}$. La letra fue escrita por Julia Ward Howe en 1861 bajo el nombre "The Battle Hymn of the Republic" y se convirtió en un himno abolicionista. Fue muy popular durante la Guerra Civil Americana y hoy día es considerada una canción patriótica.

Otro caso de culturema bíblico es la expresión Let my people go (Éxodo, 7:26). En este pasaje bíblico se hace referencia a la petición que Moisés hizo al faraón de Egipto por orden de Dios para que liberara al pueblo israelita. Este pasaje ha sido inmortalizado en el espiritual negro Go Down Moses $^{52}$ de finales del siglo XIX. Posteriormente William Faulkner tituló a su colección de cuentos cortos Go Down, Moses (1942) por esta canción. Esta expresión ha sido muy utilizada a lo largo de la historia más reciente de los EEUU ya que la canción hace referencia a los esclavos negros. Es una frase muy utilizada en muchas series y películas modernas.

Otras expresiones bíblicas que han dado origen a títulos de novelas y posteriormente algunas a títulos de películas son entre otras:

1. Eyeless in Gaza (Jueces 16:1-3). Esta expresión significa 'en estado de indefensión en un entorno hostil y alude a Sansón'. Es el título de una novela autobiográfica de Aldous Huxley (1936).

2. East of Eden (génesis 4:16). Esta expresión significa 'un lugar o situación desolado, lugar de exilio'. Es el título intencional de una novela de John Steinbeck (1952) de la que posteriormente se haría una película homónima dirigida por Elia Kazan en 1955.

3. Absalom (Samuel 13:18). Esta expresión alude al 'arquetipo de hijo rebelde que encuentra un mal fin'. Ha dado origen a la novela homónima de William Faulkner (1936).

No obstante, la rica intertextualidad de la que gozan los culturemas bíblicos ingleses no es algo común ni aplicable a la realidad española. En este sentido hay que hablar de un desfase objetivo: las diferencias entre la liturgia protestante en Estados Unidos y en Inglaterra (además de otros países de habla inglesa) frente a la liturgia católica española. En la liturgia protestante es algo común cantar canciones. A través del canto, los hablantes memorizan y tienen a su disposición un número mucho mayor de frases hechas, palabras en sentido figurado, alusiones bíblicas, etc., que los hablantes españoles. En España, la liturgia no incluye tan comúnmente el canto de canciones y hasta hace no mucho tiempo las pocas que se cantaban se hacían en latín. Hoy en día, las canciones que se emplean en la liturgia no tienen un gran impacto en el habla de la comunidad cristiana española.

\section{FALSOS AMIGOS CULTUROLÓGICOS EN LAS EXPRESIONES BÍBLICAS}

Como hemos señalado anteriormente, los hablantes ingleses y españoles pueden conceptualizar un mismo pasaje o evento bíblico de diferente manera, es decir, para un mismo

\footnotetext{
51 La primera estrofa de la canción dice: Mine eyes have seen the glory of the coming of the Lord/ He is trampling out the vintage where the grapes of wrath are stored/ He hath loosed the fateful lightning of His terrible swift sword/ His truth is marching on.

52 El espiritual negro dice así: When Israel was in Egypt's land: Let my people go,/Oppress 'd so hard they could not stand, Let my People go./Go down, Moses,/Way down in Egypt land,/Tell old Pharaoh, Let my people go.
} 
significado tendríamos dos formas distintas de expresarlo. Así, para referirse a épocas de bonanza y épocas de escasez el inglés utiliza la expresión fat years and lean years (Génesis 41:25-27) mientras que el español habla de vacas gordas y vacas flacas. En este caso se podría afirmar que mientras que el inglés es más literal, el español utiliza el símbolo de las vacas para referirse a la misma realidad (a los años buenos y a los años malos). Otro ejemplo de mismo significado conceptualizado de forma diferente lo encontramos en la expresión feeding the five thousand (Mateo 14:13-21) que hace alusión al pasaje bíblico del milagro de los panes y los peces. Aquí se da el caso opuesto que en el ejemplo anterior, en este caso es el ejemplo español el que es más explícito y literal que el inglés.

Mediante la comparación de expresiones bíblicas en inglés y en español se comprueba la existencia de expresiones que presentan la misma forma en inglés y en español, pero cuyo significado varía ligeramente de una lengua a otra. Estos ejemplos son los que se denominan 'falsos amigos culturológicos'. La importancia de conocer estos falsos amigos culturológicos radica en el hecho de que uno ha de saber, como hablante culto de ambas lenguas, las implicaciones semántico-pragmáticas de una determinada expresión bíblica y no confiarse demasiado en la proximidad cultural de ambas lenguas en materia de religión.

Como caso de falso amigo culturológico, es decir, aquel que comparte la misma forma pero distinto significado (aunque la mayoría de las veces sean matices de significado lo que distingue ambos ejemplos en inglés y en español) encontramos la expresión proverbial inglesa do not let your left hand know what your right hand is doing (Mateo 6:3-4). Esta expresión significa en inglés que la persona que haga obras de buena voluntad no debe hacer ostentación de las mismas. No obstante, en español esta expresión no se utiliza con este significado sino con el significado de ser receloso en cuanto a la propia información, es decir, a mantener en el más estricto secreto aquello que se piensa o se hace para evitar problemas con los demás.

Otro caso de falso amigo lo encontramos también en las diferentes traducciones de la Biblia. Así, Dobrovol'skij y Piirainen (2005: 103) citan el caso de las traducciones del verso bíblico que aparece en Mateo 7:6. En inglés se traduce como to cast pearls before swine, con el sentido de 'to waste gifts on those who are too uncultured to appreciate them'. Los autores señalan el uso de la palabra swine que es poco corriente en vez de la más usual pig. Igual ocurren en francés des perles aux pourceaux/aux cochons, donde el término más antiguo pourceaux coexiste junto al más moderno cochons. En italiano gettare le perle/ le margherite ai porci, en serbio Biser ne valja pred svinje bacati. En español aparecen dos versiones echar perlas a los cerdos y echar margaritas a los cerdos. 'Margarita' es el nombre de una flor en español y resulta un poco surrealista la idea de llevarles o darles de comer flores a los cerdos, sin embargo es la versión que tiene más apariciones en las bases de datos (un 15\% más). La frase en versión original es:

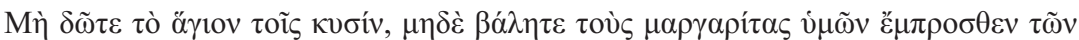

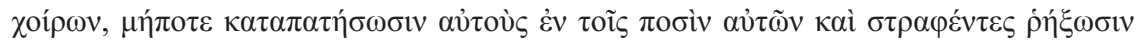

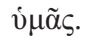

(Lit. No déis lo santo a los perros, ni echéis las perlas delante de los cerdos no sea que las pisoteen con sus pies y volviéndose os despedacen). 
Según Corominas y Pascual (1980: 851), margarita (tomado del lat. margarita 'perla' y este del griego $\mu \alpha \rho \gamma \alpha \rho i ́ \tau \eta \varsigma)$ en el sentido de 'perla' es voz culta, con escaso arraigo en el Siglo de Oro, y hoy desusada. En cualquier caso, resulta evidente que si se traduce 'margarita' en vez de 'perla', el eslabón motivacional se pierde con lo que se puede considerar un ejemplo de mala traducción.

\section{CONCLUSIONES}

A lo largo de este trabajo se ha podido comprobar la importancia que ha tenido y tiene la Biblia en la creación de expresiones fraseológicas en todas las lenguas europeas. Estas expresiones son denominadas en español de diferentes modos: bibleismos, biblismos o biblicismos.

Mediante el estudio comparativo de las expresiones bíblicas en inglés y en español se ha llegado a la conclusión de que la Biblia y la lectura de la misma ha cumplido una función más significativa en los países protestantes que en los países católicos, de ahí que los fraseologismos provenientes de las Sagradas Escrituras sean mucho más abundantes y conocidos (en el uso cotidiano) en el ámbito de las culturas de habla inglesa que en las culturas de habla española. Otro aspecto que fundamenta la mayor importancia que la Biblia tiene en el día a día de los hablantes de habla inglesa es la extensa bibliografía que existe al respecto de las expresiones de origen bíblico en forma de compendios, diccionarios de alusiones, diccionario de proverbios, diccionarios de imágenes bíblicas, etc ${ }^{53}$. En español no encontramos obras parecidas, excepto por las traducciones al español que se han hecho de obras escritas originalmente en inglés, como por ejemplo el diccionario de Browning $(1996)^{54}$.

Además, mediante el estudio de la intertextualidad de las expresiones bíblicas en inglés y en español, se llega a la conclusión de que el número de culturemas bíblicos es mucho mayor en inglés que en español. La riqueza que tiene el inglés y la creatividad en expresiones bíblicas de uso común es también mucho mayor que la del español. Se ha comprobado que existe una mayor influencia de la Biblia en los países de habla inglesa que en los países de habla española y se ha llegado a la conclusión que en relación con este aspecto no se pueden comparar ambas tradiciones litúrgicas, ya que, mientras que los pueblos de habla inglesa sí que mantienen una liturgia viva, esta es prácticamente inexistente en el ámbito español ${ }^{55}$.

\section{REFERENCIAS BIBLIOGRÁFICAS}

Dobrovol'skis, Dmitrij y PiIRAInen, Elizabeth (2005a). Figurative language: Crosscultural and crosslinguistic perspectives. Oxford: Elsevier.

Fulghum, Walter B. (1965). A Dictionary of Biblical Allusions in English Literature.

\footnotetext{
53 Véanse entre otros: Fulghum, (1965); Jeffrey (1992); Selman y Manser (1998); Ryken, Wilhoit y Longman (1998); Manser (2003); Tischler, (2006);

54 Browning, W.R.F. (1996): Oxford Dictionary of the Bible. Oxford: O.U.P. (Traducción al español por J.P. Tosaus Abadía, Diccionario de la Biblia: Guía básica sobre los temas, personajes y lugares bíblicos, 1998. Barcelona: Paidós Ibérica).

55 Quizás se mantenga hoy en día en mayor grado en América Latina.
} 
Austin, Tex.: Holt, Rinehart and Winston.

GaK, V. (1998). "Probleme der kontrastiven Phraseologie: Biblische Phraseologismen in der russischen und in der französischen Sprache". En Eismann, W. (ed.), EUROPHRAS 95. Europäische Phraseologie im Vergleich: Gemeinsames Erbe und kulturelle Vielfalt, Brockmeyer, pp. 237-246.

JEFFrey, David Lyle (ed.) (1992). A Dictionary of Biblical Tradition in English Literature. Grand Rapids, Mich.: William B. Eerdmans.

LuQue NADAL, Lucía (2009). "Los culturemas: ¿unidades lingüísticas, ideológicas o culturales?” Language Design 11 (2009: 93-120).

Manser, Martin H. (2003). The Facts On File Dictionary of Classical and Biblical Allusions. New York: Facts On File, Inc.

Mellado Blanco, Carmen (2007). "La Biblia como fuente de idiomaticidad en alemán y español”. En Luque Durán, J.D. y Pamies Bertrán, A. (eds.) (2007), pp. 99- 108.

Ryken, L.; Wilhoit, J.C. y Longman, T. (eds.) (1998). Dictionary of Biblical Imaginery. Downers Grove:InterVarsity Press.

SABBAn, A. (2007). "Culture-boundness and problems of cross-cultural phraseology". En Burger, H., D. Dobrovol'skij, P. Kühn y N. R. Norrick (eds.): Phraseology. An International Handbook of Contemporary Research, 590-605. Berlin: de Gruyter.

Selman, Martin J., y Manser, Martin H. (1998). The Hearthside Bible Dictionary. Nashville, Tenn.: Cumberland House.

Tischler, Nancy M. (2006). All Things in the Bible. An Encyclopedia of the Biblical World (2 vols). Westport: Greenwood Press.

Wierzbicka, Anna (2001). What did Jesus mean?: explaining the Sermon on the Mount and the parables in simple and human concepts. Oxford: Oxford University Press. 